\title{
Diagnostic Predicament of Cystic Degenerated Uterine Leiomyoma Presenting as Ovarian Cyst: A Case Report
}

\author{
${ }^{1}$ Mayanglambam R Devi, ${ }^{2}$ Helen Kamei, ${ }^{3}$ Paikhomba Kharibam, ${ }^{4}$ Sylvia Keisham, ${ }^{5}$ Sunita Haobam
}

\begin{abstract}
A large degenerated fibroid may give a false impression of other abdominal gynecological abnormalities like in our case of a 46-year-old para 3, living 3 (P3L3) woman presented to our hospital with the complaint of distension of abdomen since last ten years. The increase in the size of the abdomen was slow initially, but it increased rapidly in last one month. She complained of right abdominal pain for the last one month along with difficulty in breathing and constipation. Abdomen examination revealed a huge abdominopelvic mass and a provisional diagnosis of the ovarian cyst was made clinically. Computed tomography (CT) scan showed a very large cystic lesion arising from the pelvis filling up the abdominal cavity. We planned for laparotomy and proceed. Intraoperatively, a giant cyst occupying the whole abdomen identified and control suction done with removal of $\sim 5$ liters of straw-colored fluid. The cyst was found to have adhered to the mesentery and also attached to the fundal area of the uterus. The cyst was severed from the uterus by clamping and cutting the pedicle of the cyst. Uterus and bilateral ovaries were looking normal. Total abdominal hysterectomy with bilateral salpingo-oophorectomy done. Cyst separated from guts and excised. Feeding vessels were from the mesenteric artery. Histopathological examination showed the features of leiomyoma with cystic degeneration. Leiomyoma with cystic degeneration is the rare secondary changes. But they can cause a diagnostic dilemma by mimicking huge ovarian cyst.
\end{abstract}

Keywords: Cystic degeneration, Leiomyoma, Ovarian cyst.

How to cite this article: Devi MR, Kamei H, Kharibam $\mathrm{P}$, Keisham S, Haobam S. Diagnostic Predicament of Cystic Degenerated Uterine Leiomyoma Presenting as Ovarian Cyst: A Case Report. J South Asian Feder Menopause Soc 2018;6(2):126-128.

Source of support: Nil

Conflict of interest: None

Date of received: 10 January 2018

Date of acceptance: 27 January 2018

Date of publication: July 2018

\footnotetext{
${ }^{1}$ Senior Resident, ${ }^{2,5}$ Associate Professor, ${ }^{3}$ Assistant Professor, ${ }^{4}$ Postgraduate Trainee

${ }^{1-4}$ Department of Obstetrics and Gynecology, Jawaharlal Nehru Institute of Medical Sciences, Imphal, Manipur, India

${ }^{5}$ Department of Pathology, Jawaharlal Nehru Institute of Medical Sciences, Imphal, Manipur, India

Corresponding Author: Mayanglambam R Devi, Senior Resident, Department of Obstetrics and Gynecology, Jawaharlal Nehru Institute of Medical Sciences, Imphal, Manipur, India, e-mail: mronitadevi@rediffmail.com
}

\section{INTRODUCTION}

Fibroids are benign, monoclonal tumors of the smooth muscle cells of the myometrium and contain large aggregations of the extracellular matrix. ${ }^{1}$ It is the most common uterine neoplasm, with a prevalence of 20 to $30 \%$ in patients older than 30 years. ${ }^{2}$ Though with the help of modern imaging modalities it is easier to make a diagnosis before the surgical intervention, still in some cases, the large size of masses may give a false impression of other abdominal gynecological abnormalities. Isolated case reports of a diagnostic dilemma in huge uterine fibroid have been reported, but exact incidence is not known.

\section{CASE REPORT}

A 46-year-old lady, P3L3 presented to our gynecological outpatient department (OPD) of JNIMS with the chief complaint of abdomen distension since last ten years. The increase in the size of the abdomen was slow initially, but it increased rapidly in last one month, initially, it was not any pain or discomfort, but she complained of right abdominal pain for the previous one month along with difficulty of breathing and constipation. Her bladder habit was normal. Her menstrual cycle was also normal. No significant medical or surgical history was there. Abdomen examination showed a tense, overtly distended abdomen (Fig. 1). On percussion, the abdomen was dull all throughout the four quadrants. Ultrasound abdomen was suggestive of complex cystic space occupying lesion measuring $276 \times 173$

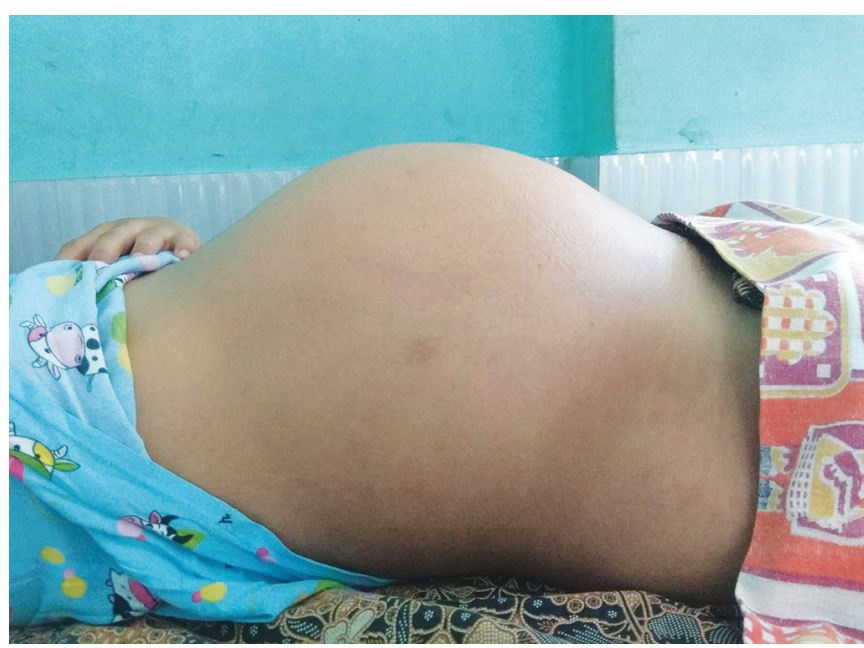

Fig. 1: Tense distended abdomen 


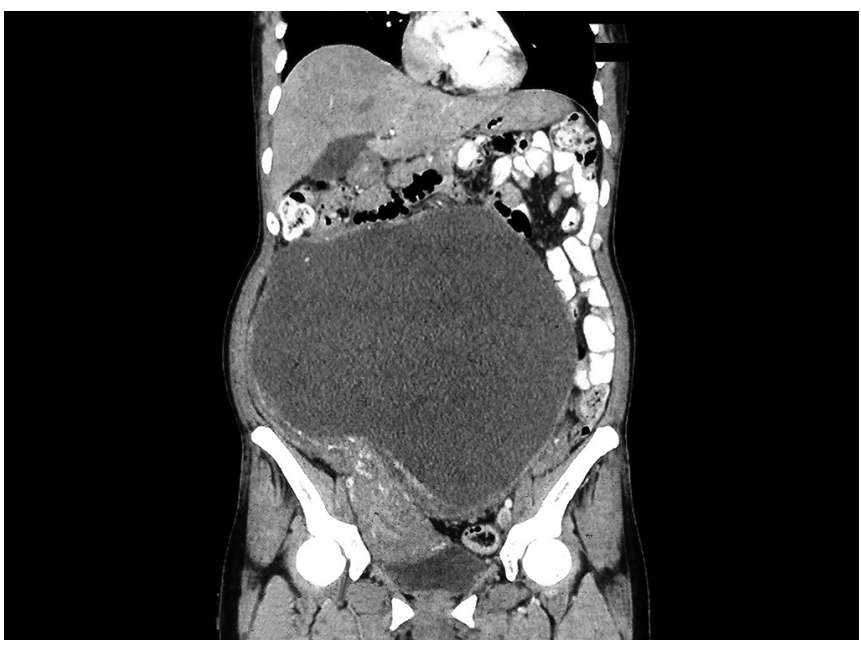

Fig. 2: Coronal section of CT scan showing a cystic mass arising from the pelvis suggesting ovarian mass

$\mathrm{mm}$ with low-level internal echoes and soft tissue component seen extending from the epigastric region, paraumbilical region, both flanks and pelvis. CT scan showed a very large oval shaped cystic mass lesion of size $18 \times 27 \times 26 \mathrm{~cm}$ $(\mathrm{AP} \times \mathrm{RL} \times \mathrm{SI})$ was seen arising from right ovary causing significant mass effect resulting in the displacement of the bowel loops (Fig. 2). Left ovary and uterus looking normal. The lesion is seen in contact with the left uterine wall with loss of fat plane separation adhered? Free fluid aspirate analysis showed mesothelial cell, lymphocytic cells $90 \%$, no malignant cells, and normal ADA level. Baseline investigations were within the normal range except Ca 125 report was $125 \mathrm{U} / \mathrm{mL}$. Pap smear was inflammatory. The patient was planned for laparotomy with the proceeding. Introperatively, a big cyst occupying the whole abdomen identified and control suction was done to reduce the cyst size, removing of $\sim 5$ liters of straw-colored fluid, the cyst was found adhered to mesentery looking like a mesenteric cyst. The cyst was attached to the fundus of the uterus by a thick pedicle, and that was clamped, cut, and ligated

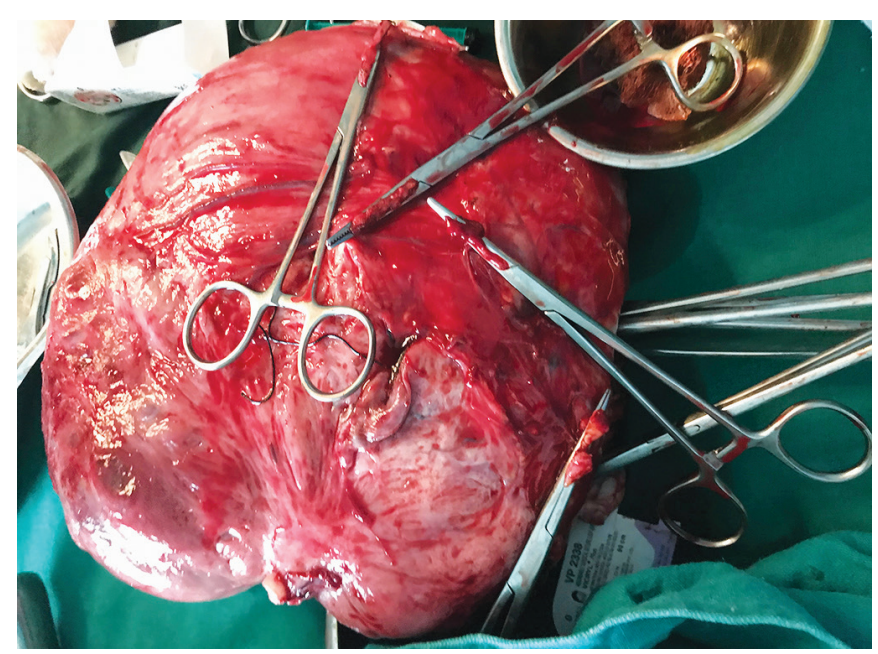

Fig. 4: Postoperative specimen measuring $21 \mathrm{~cm} \times 20 \mathrm{~cm} \times 8 \mathrm{~cm}$

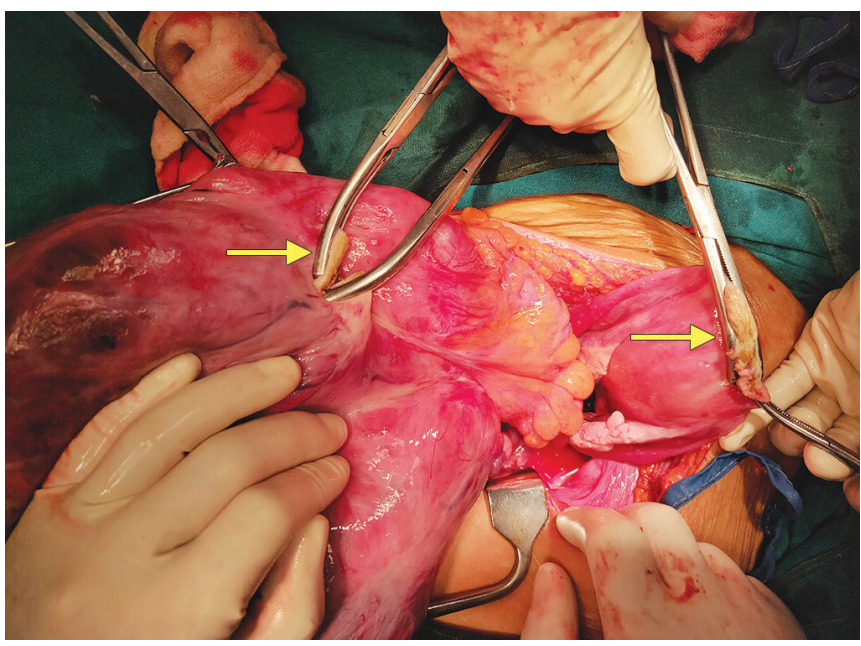

Fig. 3: Intraoperative finding of the mass showing its attachment to the uterine fundus

(Fig. 3). Large mass after removal is showing in Figure 4. The uterus and bilateral ovaries were looking normal. Total abdominal hysterectomy with bilateral salpingooophorectomy done. Cyst enucleation done separately from the mesentery and gut.

The cyst was measured $21 \times 20 \times 8 \mathrm{~cm}$, and on cutsection showed a large cyst containing blood-tinged fluid, a smooth inner surface, and solid areas identified, and the cut surface of the solid areas was firm and grey-white. Histopathology finding of the uterus, bilateral tubes and ovaries are unremarkable. Multiple sections studied from the sent specimen showed a large cyst without any epithelial or mesothelial lining but with the presence of hemosiderin-laden macrophages (Fig. 5). Sections from the solid areas showed benign spindle cells arranged in short intersecting fascicles and occasional whorled pattern (Fig. 6). Features were of leiomyoma with cystic degeneration. Postoperative period was uneventful. The patient was discharged on day 6 of the operation in stable condition.

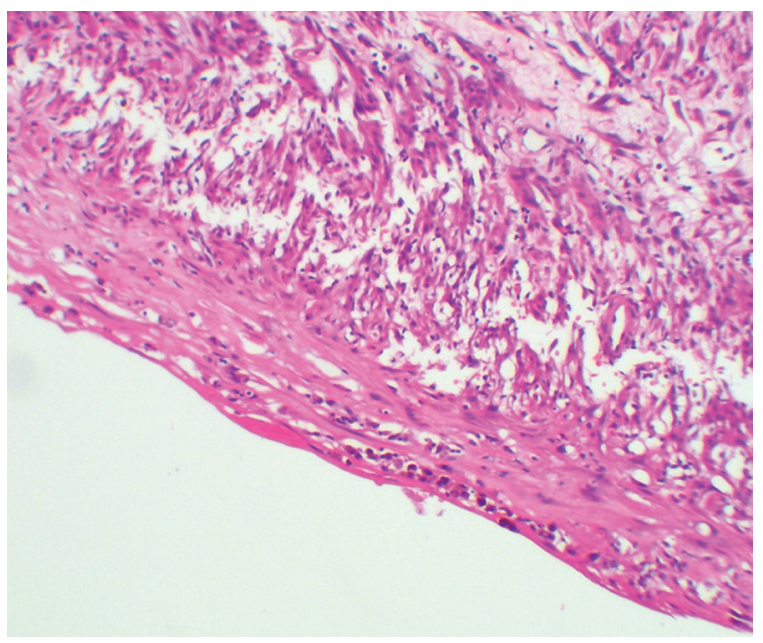

Fig. 5: Microscopic picture of cyst wall without any epithelial or mesothelial lining but with presence of hemosiderin laden macrophages 


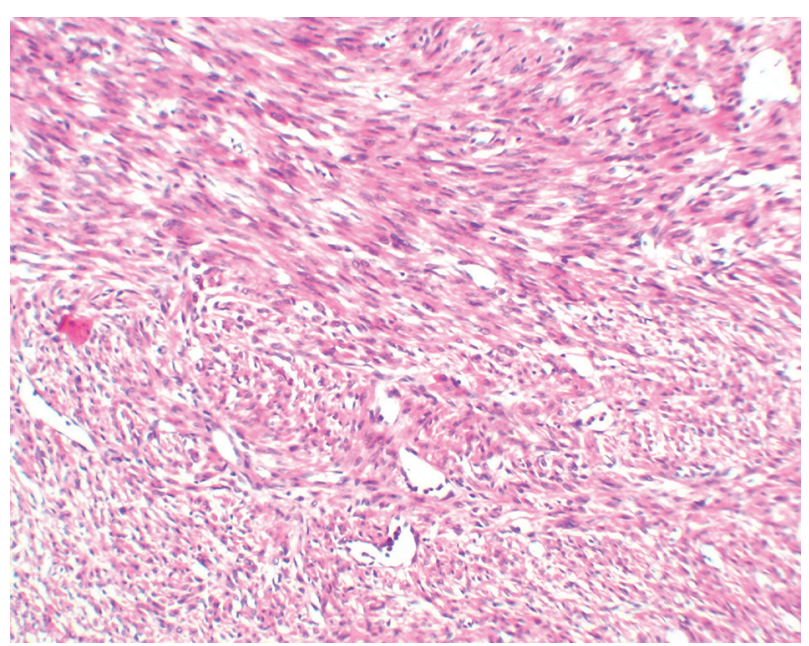

Fig. 6: Microscopic picture of leiomyoma showing benign spindle cells arranged in short intersecting fascicles and occasional whorled pattern

\section{DISCUSSION}

Fibroids may be submucosal, intramural, subserosal. As fibroids enlarge they outgrow their blood supply, which causes various types of degeneration, most commonly hyaline, myxoid, cystic, or red degeneration. ${ }^{3}$ The type of degeneration depends on the degree and rapidity of onset of vascular insufficiency. Hyaline degeneration is the most common change in leiomyomas $(60 \%){ }^{4}$ Gradually the areas of hyalinization may undergo liquefaction and cystic cavities filled with clear liquid. Cystic degeneration is seen in $4 \%$ of leiomyomas. Sometimes the cystic change is so great that it can become a cystic tumor.

Mohammad et al. reported a case of extensive cystic degeneration in a pelvic leiomyoma mimicking ovarian cystic neoplasm, but it was not connected with a uterus. ${ }^{5}$ But in our case, the cyst was attached to the fundal area of the uterus by a small pedicle. Sonawane et al.also reported a case of giant leiomyoma with cystic degeneration, that adhered to the uterus, ovary, and mesentery, and caused a diagnostic dilemma. ${ }^{6}$ In our case also, the cyst was attached to uterus and mesentery. Sipra et al. also reported a case of giant retroperitoneal leiomyoma with cystic degeneration mimicking a huge ovarian cyst. ${ }^{7}$ Though CT scan was guiding towards retroperitoneal lesion its cystic nature created a diagnostic dilemma. In our case also CT scan was guiding towards the ovarian mass but it came out as degenerated leiomyoma. In a case study by Chowdhury et al., ${ }^{8}$ the CT scan abdomen revealed a large abdominopelvic mass likely ovarian mucinous-cystadenoma but it came out as a fibroid, and myomectomy was done, by preserving uterus and both the ovaries.

\section{CONCLUSION}

Although fibroids usually have a characteristic sonographic appearance, degenerating fibroids can have variable patterns and cause a diagnostic challenge by mimicking an ovarian tumor. Correlation of clinical, sonographic and intraoperative findings can lead to the correct diagnosis and effective treatment. However, degenerative changes/massive size may cause confusion in the diagnosis of abdominopelvic lump. Hence, increase awareness of the possibility in such cases complicating diagnosis, may help in proper approach and management.

\section{REFERENCES}

1. Leppert PC, Catherino WH, et al. A new hypothesis about the origin of uterine fibroids based on gene expression profiling with microarrays. Am J Obstet Gynaecol 2006;195:415-420.

2. SzklarukJ, Tamm EP, et al. MR imaging of common and uncommon large pelvic masses. Radiographics2003;23:403-424.

3. Murase E, Siegelman ES, et al. Uterine leiomyomas, histopathologic features, MRI imaging findings, differential diagnosis and treatment. Radiographics 1999;19:1179-1197.

4. Kaushik C, Prasad A, et al. Case series cystic degeneration in uterine leiomyomas. Indian Journal of Radiology and Imaging, 2008;(1):69-72.

5. Arafa M, Basem EL. Extensive cystic degeneration of leiomyoma mimicking ovarian cystic neoplasm: Malayasias J Pathol 2012;34(2):165-166.

6. Sonawane SS, Ambawade VD, et al. Giant cystic leiomyoma causing diagnostic dilemma-An usual case report. Int J Res Health Sci 2015;3(1):165-168.

7. Bagchi S, Gupta AK, et al. A Rare case of Giant retroperitoneal uterine Leiomyoma with cystic degeneration mimicking huge ovarian cyst. The Southeast Asian J Case Rep Rev 2014;3(2) eISSN:675-682.

8. Chowdhury M, Gupta V, et al. Dilemma in diagnosis of huge uterine fibroid: a case report. Int J Clin Trials. 2015;2(1):25-27. 